\title{
Instrumentation and virtual library for air pollution monitoring
}

\author{
Marius Branzila \\ Technical University Gh. Asachi of Iasi \\ Romania
}

\section{Abstract}

In this work a data acquisition board (DAQB) with data transfer by serial port and the associated virtual library included into LabVIEW software are presented. The DAQB developed around a National Semiconductor LM 12458 device, have the capability to perform tasks that diminish the host processor work and is capable to communicate with the host computer by using a set of drivers associated. Highly integrated device circuit that has into it the most components of the board, facility in data handling, good metrological performance and a very low cost are the benefits of the proposed system. Using the LabView environment, we have realized a virtual instrument able to get from the prototype data acquisition board for environmental monitoring parameters the information about air pollution factors like $\mathrm{CO}, \mathrm{H} 2 \mathrm{~S}, \mathrm{SO} 2, \mathrm{NO}, \mathrm{NO} 2$ etc. In order to get effective information about those factors and the monitoring points, this intelligent measurement system, compound from portable computer, and gas detector. This system can be used to map the information about the air pollution factors dispersion in order to answer to the needs of residential and industrial areas expansion.

\section{Introduction}

The modern microcomputer technology has made it relatively simple to install, configure, and start up a high-performance data acquisition system. Experienced users will be happy to know that many of the problems encountered a few years ago are gone. New users will never realize how difficult it once was to bring up a data acquisition system. These same technology advances have made it even more difficult than ever to select among the many options. The hardware decisions facing a user today require a great deal of study, analysis, and consideration. Every system will work, but some are better than others for each particular application.

Most data acquisition hardware is compatible with most popular industrial software, or it comes with a software package of its own. Virtually all these data acquisition devices and systems have the same basic specifications and options on their data sheets: signal conditioning, number of analog input channels, sampling rate, resolution, accuracy etc. 
The most DAS's used in instrumentation are made it by National Instrument, including the software. These boards are plug-in types on ISA or PCI slots of the computers. In this case they will be affected by electromagnetic field. The manufacturer has to take special protection measures that increase the device costs.

Taking in consideration all this facts, we have developed a DAQB with data transfer by serial port. A set of drivers and functions specially designed to by access in LabVIEW functions palette we have made.

The EU-funded conference on "Environment, Health, Safety: a challenge for measurements", held in Paris in June 2001, recognized the need to improve the performance of environmental measurement systems and their harmonization at EU level, to foster the dialogue between the providers of measurement methods and the users of measurement results, and to prepare the base - by establishing special communication tools - for the integration of research expertise and resources of environmental monitoring across Europe. The concept presented herein aims to respond to this actual challenge by combining the latest software trends with the newest hardware concepts in environmental monitoring, towards providing reliable measurement results and representative environmental indicators, evaluating trends and quantifying the achieved results in order to manage the potential environmental risk in compliance with European legislation and local particularities.

In the actual development stage of the Romanian residential and industrial areas, the society demands more accurate and elaborated information in every domain. One of great interest is the air pollution filed. Over the last years, the clime changes have made the old prevision for dispersion of the air pollution around the industrial areas no longer accurate.

The atmospheric environment needs to be examined in consideration of the following three phenomena: global warming, ozone-layer depletion, air pollution.

Among these three, global warming is the most critical in terms of environmental conservation. Global warming is a result of greenhouse-gas emissions; therefore, to prevent it, greenhouse-gas emissions must be reduced. A major greenhouse gas is carbon dioxide (CO2). Therefore, reducing energy use, or saving energy, is the most effective way to help prevent global warming. There are some other gases that have a considerable influence on global warming. The first step to cutting the emissions of these gases as another environmental conservation measure is to monitor them in order to find a way to control them.

For this purpose, a new concept of performing high-speed data acquisition based on remote sensors, and an accurate transmission and processing of the meteorological parameters towards obtaining useful data for the users was developed in connection with the centre services. New methods of interconnecting hardware and dedicated software support were successfully implemented in order to increase the quality and precision of measurements.

In the same time, the Web concept itself is changing the way the measurements are made available and the results are distributed/communicated. Many different options are occurring as regards reports publishing, data sharing, and remotely controlling the applications. The LabVIEW environment was incorporated in centre concept towards creating a unique and powerful distributed application, combining together different measurement nodes and multiple users into a unique measurement controlling system, in order to integrate and revolutionize the fundamental architecture of actual PC-based measurement solutions. 
The main objective of this work is to realize an intelligent system for environmental quality control and monitoring based on specialized sensors that are connected in a unit system.

\section{System architecture}

The hardware of environmental quality monitoring systems (sensors, conditioning circuits, acquisition and communication) must usually be complemented with processing blocks to perform different tasks associated to one-dimensional or multi-dimensional data that flow on the system measurement channels.

The architecture is composed as follows: the specialized sensors, detection circuit, a prototype data acquisition board, PC-host. Using all this hardware we are able to perform a study for Taguchi-type gas sensors.

Intelligent system achievement which is dedicated for particular application is not easy. It presume a selection of chemical sensors area which provide a large information quantity and complex algorithms development for signal processing.

The developed environmental monitoring systems (EMS), that use a prototype data acquisition board, perform different tasks like: multi-sensors/multi-point measurement, continuum real-time monitoring, across limits warnings, save data etc.

Air quality parameters can be monitories, from interested areas like public places, enterprises etc. The desktop PC and LabVIEW software have the fallowing functions:

- DAQB control,

- Data processing and results display,

- Data storage and data administration

- User warning,

- Analysis and decision etc.

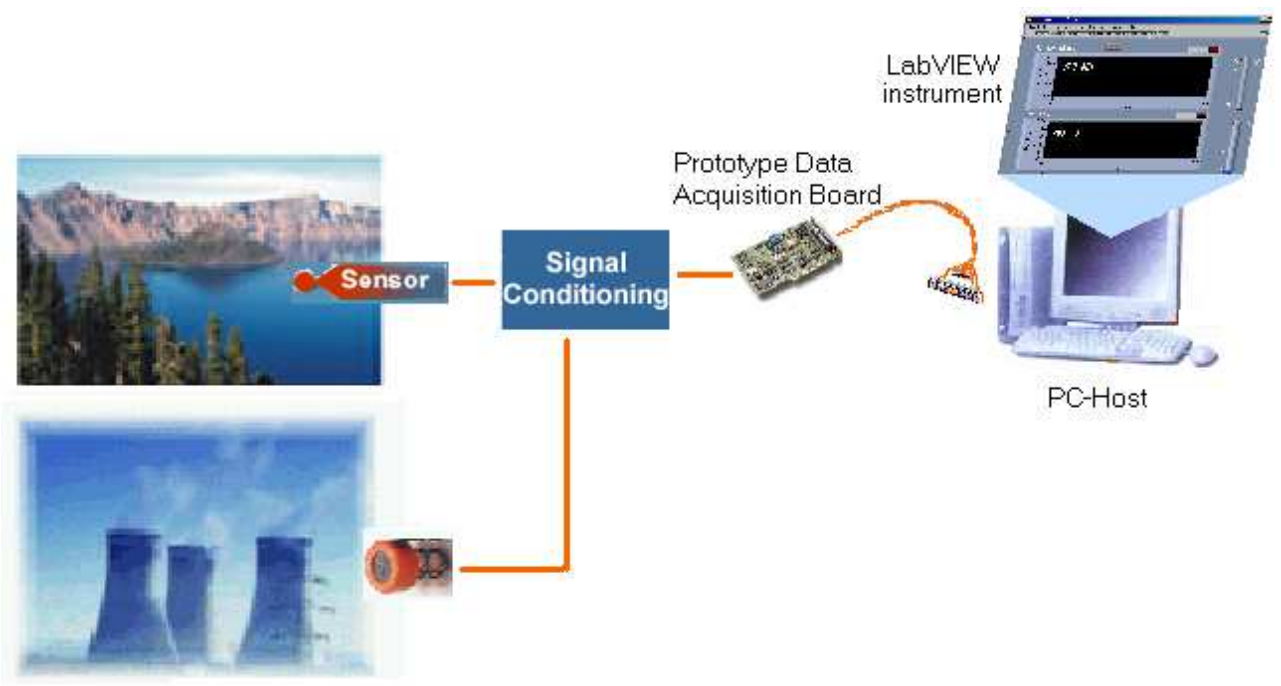

Fig. 1. System architecture. 


\subsection{Data acquisition system}

The data acquisition system is a low cost board realized around the chip LM12H458 that is an integrated DAS and offers a self-calibrating 12-bit a sign A/D converter with choice of single ended, fully differential, or mixed inputs, with on-chip differential reference, 8-input analog multiplexer, sample-and-hold, an impressive, flexible programmable logic system and a choice of speed/power combinations. The programmable logic has the circuitry to perform a number of tasks on its own, freeing the host processor for other tasks. This logic includes:

1. An instruction RAM that allows the DAS to function on its own (after being programmed by the host processor) with programmable acquisition time, input selection, 8-bit or 12-bit conversion mode.

2. Limit registers for comparison of the inputs against high and low limits in the "watchdog" mode.

3. A 32-word FIFO register to store conversion results until read by the host.

4. Interrupt control logic with interrupt generation for 8 different conditions.

5. A 16-bit timer register.

6. Circuitry to synchronize signal acquisition with external events.

7. A parallel microprocessor/microcontroller interface with selectable 8-bit or 16-bit data access.

The board can be used to develop both software and hardware. Since the parallel port is limited to 8-bit bidirectional data transfers, the BW pin is tied high for 8-bit access. Multiplexed address/data bus architecture was used. The circuit operates on a single $+5 \mathrm{~V}$ supply derived from the external supply using an LM7805 regulator or from USB port. This greatly attenuates noise that may be present on the computer's power supply lines.

Digital and analog supply pins are connected together to the same supply voltage but they need separate, multiple bypass capacitors. Multiple capacitors on the supply pins and the reference inputs ensure a low impedance bypass path over a wide frequency range.

All digital interface control signals (/RD, /WR, ALE, /INT, /CS), data lines (DB0-DB7), address lines (A0-A4) connections are made through the microcontroller pins ports.

All analog signals applied to, or received by, the input multiplexer (IN0-IN7), $\mathrm{V}_{\text {REF+ }}, \mathrm{V}_{\mathrm{REF}-}$, $\mathrm{V}_{\text {REFOUT, }}$ and the SYNC signal input/output are applied through a connector on the rear side of the board.

The voltage applied to $\mathrm{V}_{\mathrm{REF}}-$ is GND and $\mathrm{V}_{\mathrm{REF}}$ is selected using a jumper. This jumper selects between the LM12H458 internal reference output, $\mathrm{V}_{\text {REFOUT, }}$ and the voltage applied to the corresponding pin applies it to the LM12H458 $\mathrm{V}_{\mathrm{REF}+}$ input.

A SYNK push button is available on the DAQB. With signal SYNC configured as an input, it is possible to synchronize the start of a conversion to an external event. This is useful in applications such as digital signal processing (DSP) where the exact timing of conversions is important.

Because the LM12H458 is so versatile, working with them may appear to be an overwhelming task. However, gaining a basic understanding of the device will prove to be fairly easy and using it to be as easy as programming the host microprocessor or microcontroller (AT90S8515).

The DAS is designed to be controlled by a processor, but the DAS functionality off loads most of the data acquisition burden from the processor, resulting in a great reduction of software and processor overhead. The processor downloads a set of operational instructions 
to the DAS RAM and registers, and then issues a start command to the DAS, which performs conversions and/or comparisons as indicated by the instructions, loading conversion results into the FIFO, while the processor is free to do other chores, or can be idled, if not needed.

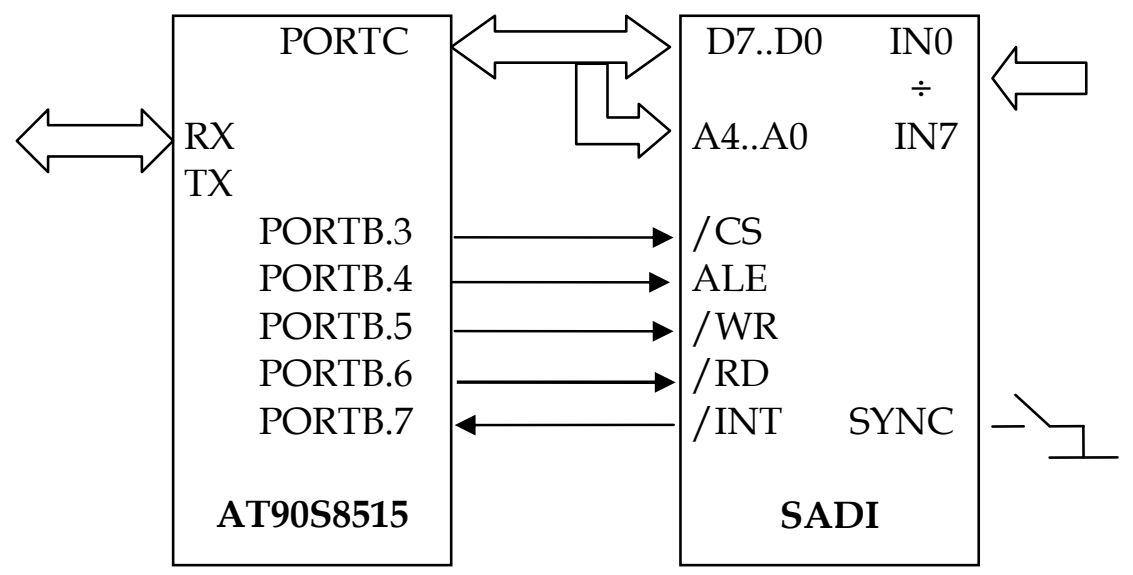

Fig. 2. The DAQB architecture design.

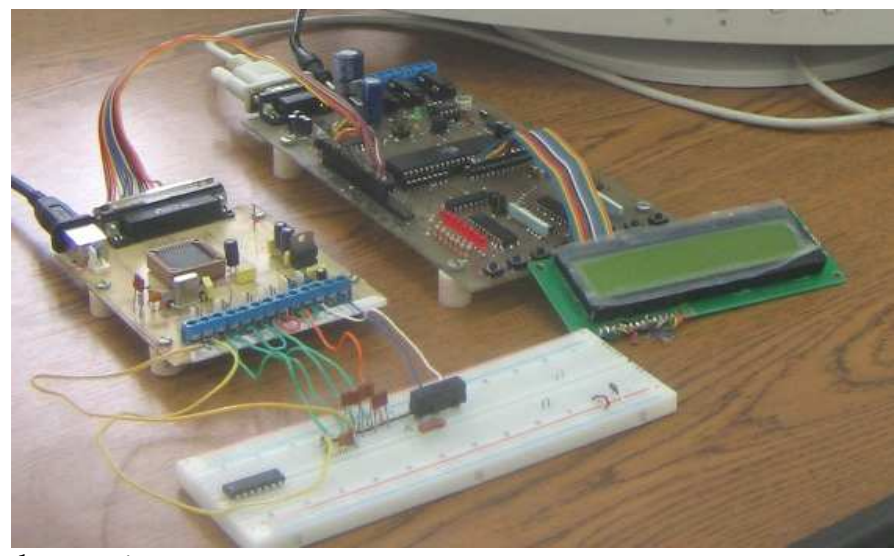

Fig. 3. The hardware picture.

After the DAS starts operating, the processor may respond to interrupts from the DAS, or it may interrogate the DAS at any time.

The architecture design and the hardware picture are presented in figures 2 and 3.

The main features of our DAQB are: 4 full-differential channels, $12+$ sign ADC resolution, 100 ksamples acquisition rate, 20 ksamples transfer rate, 1 LSB linearity, 0,5 LSB accuracy, auto-zero and full calibration procedures, $\pm 5 \mathrm{~V}$ input voltage span, $30 \mathrm{~mW}$ power dissipation. In Table 1 we present the obtained results using the new DAQB and different apparatus. 


\begin{tabular}{|c|c|c|c|c|}
\hline Nr. & $\begin{array}{c}\text { GEN DC } \\
{[\mathrm{V}]}\end{array}$ & $\begin{array}{c}\text { New } \\
\text { DAQB } \\
{[\mathrm{V}]}\end{array}$ & $\begin{array}{c}\text { KEITHLEY } \\
\mathbf{2 0 0 0} \\
{[\mathrm{V}]}\end{array}$ & $\begin{array}{c}\text { METERMAN } \\
\text { 38XR } \\
{[\mathrm{V}]}\end{array}$ \\
\hline 1 & 0.010 & 0.0117 & 0.0116 & 0.0114 \\
\hline 2 & 0.020 & 0.0218 & 0.0216 & 0.0213 \\
\hline 3 & 0.040 & 0.0425 & 0.0418 & 0.0414 \\
\hline 4 & 0.060 & 0.0621 & 0.0618 & 0.0615 \\
\hline 5 & 0.080 & 0.0825 & 0.0819 & 0.0816 \\
\hline 6 & 0.100 & 0.0102 & 0.1018 & 0.1015 \\
\hline 7 & 0.500 & 0.0505 & 0.5036 & 0.5034 \\
\hline 8 & 1.000 & 1.0100 & 1.0060 & 1,0020 \\
\hline 9 & 1.500 & 1.5130 & 1.5070 & 1,5040 \\
\hline 10 & 1.700 & 1.7150 & 1.7080 & 1,7050 \\
\hline 11 & 2.000 & 2.0180 & 2.0090 & 2,0060 \\
\hline 12 & 2.200 & 2.2190 & 2.2100 & 2,2070 \\
\hline 13 & 2.400 & 2.4220 & 2.4110 & 2,4070 \\
\hline 14 & 2.500 & 2.4994 & 2.5120 & 2,5090 \\
\hline
\end{tabular}

Table 1. Comparative results obtained using new DAQB and different apparatus.

DAQB presented have the capability to perform tasks that diminish the host processor work and is capable to communicate with the host computer by using a set of drivers associated in LabVIEW software. The novelty of the system mostly consists in the drivers and functions associated that are gathered into a library easily accessed by LabVIEW and assure the flexibility and the portability of the system. One of the performances consist in the fact that you can plug-in the DAQB to the running host computer externally.

$\mathrm{DAQB}$ is simple, versatile, flexible, cheap, high-speed digital data acquisition system that combined with LabVIEW software, become a very useful measurement instrument.

\subsection{The sensors module}

The sensitive elements included in analyzed environment are metal oxide semiconductor mainly composed of $\mathrm{SnO} 2$ and are tied to the EMS. These elements are heated at a suitable operating temperature by a built-in heater. Exposure of the sensor to a vapour produces a large change in its electrical resistance. In fresh air the sensor resistance is high. When a combustible gas such as propane, methane etc. comes in contact with the sensor surface, the sensor resistance decreases in accordance with the present gas concentration (Fig. 4.a). Semiconductor gas sensors based on $\mathrm{SnO} 2$ are widely used as safety monitors for detecting most combustible and pollution gases. However, most of the commercial gas sensors are not selective enough to detect a single chemical species in a gaseous mixture. It is desirable that a single sensor should be able to selectively detect several kinds of gases.

Recently, new methods have been proposed for chemical sensing that utilizes the analysis of the stochastic component of the sensor signal in Taguchi type sensors. It has been shown that even a single sensor may be sufficient for realizing a powerful electronic nose.

One of the problems appearing when we use sensitive elements like metal oxide semiconductor $(\mathrm{SnO} 2)$ is the temperature and humidity dependence of sensibility characteristic. 
In this case the influences of physical environmental parameters must be compensated.

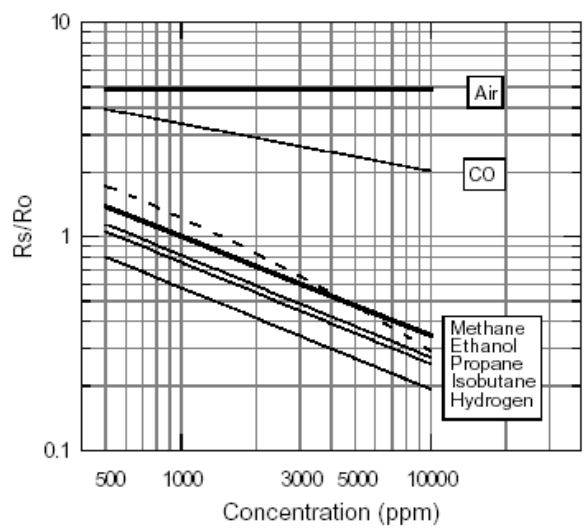

a.

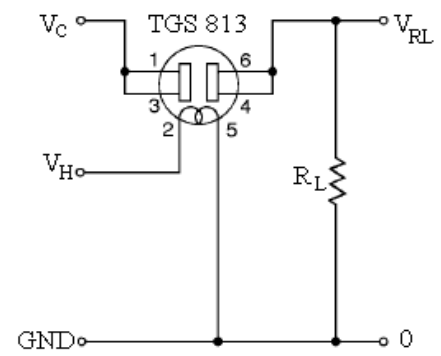

b.

Fig. 4. Sensitivity characteristics and detection circuit for a Figarosensor.

The signal conditioning circuits (Fig. 4.b) associated with Figaro gas sensors (TGS813, TGS 822), have the function to convert $\Delta R$ s variation of sensor resistance in $\Delta V$ variation of voltage.

The change in the sensor resistance is obtained as the change of the output voltage across the load resistor (RL) in series whit the sensor resistance (RS). The constant $5 \mathrm{~V}$ output of the data acquisition board is available for the heater of the sensor $(\mathrm{VH})$ and for the detecting circuit (VC). The relationship between RS and VRL is expressed by the following equation.

$$
\mathrm{Rs}=\frac{\mathrm{V}_{\mathrm{C}}-V_{R_{L}}}{\mathrm{~V}_{\mathrm{R}}} \cdot \mathrm{R}_{\mathrm{L}}[\Omega]
$$

The interaction of the chemical with the surface and bulk of the sensor induces spontaneous fluctuations. Recently, new methods have been proposed for chemical sensing that utilizes the analysis of the stochastic component of the sensor signal in Taguchi type sensors. It has been shown that even a single sensor may be sufficient for realizing a powerful electronic nose. However, there are no studies of the power spectrum in different types of commercial gas sensors under different gas atmospheres. This paper studies the stochastic signal in commercial semiconductor gas sensors measured under different atmospheres.

A unique gas detection block is used for both architectures of the system. It contains an array of five sensors and the corresponding detection circuits (Fig. 5).

To detect hydrogen sulfide (H2S), ammonia (NH3) and combustible gases we use Taguchi type gas sensors produced by Figaro Co. The detection principle of TGS sensors is based on chemical adsorption and desorption of gases on the sensor surface. The sensing element is a tin dioxide $(\mathrm{SnO} 2)$ semiconductor that is heated at a suitable operating temperature by a built-in heater. In the presence of a detectable gas, the sensor conductivity increases 
depending on the gas concentration in the air. A simple electrical circuit converts the change in the sensor resistance to an output voltage, which corresponds to the gas concentration.

TGS 813 sensor has a good sensitivity to a wide range of combustible gases for concentrations from several ppm to over $10,000 \mathrm{ppm}$. Because of poor sensor selectivity, it is used only to detect the presence of some flammable gases in the environment (methane, ethanol, isobutane, and hydrogen).

TGS 825 and TGS 826 sensors have good sensitivity and selectivity to H2S and NH3, respectively. The relationship of sensor resistance to gas concentration is non-linear within the practical range of gas concentration (from several ppm to $100 \mathrm{ppm}$ ). In the data processing part, two artificial neural networks approximate the sensitivity characteristics of these sensors for the continual measurement of $\mathrm{H} 2 \mathrm{~S}$ and $\mathrm{NH} 3$ concentration.

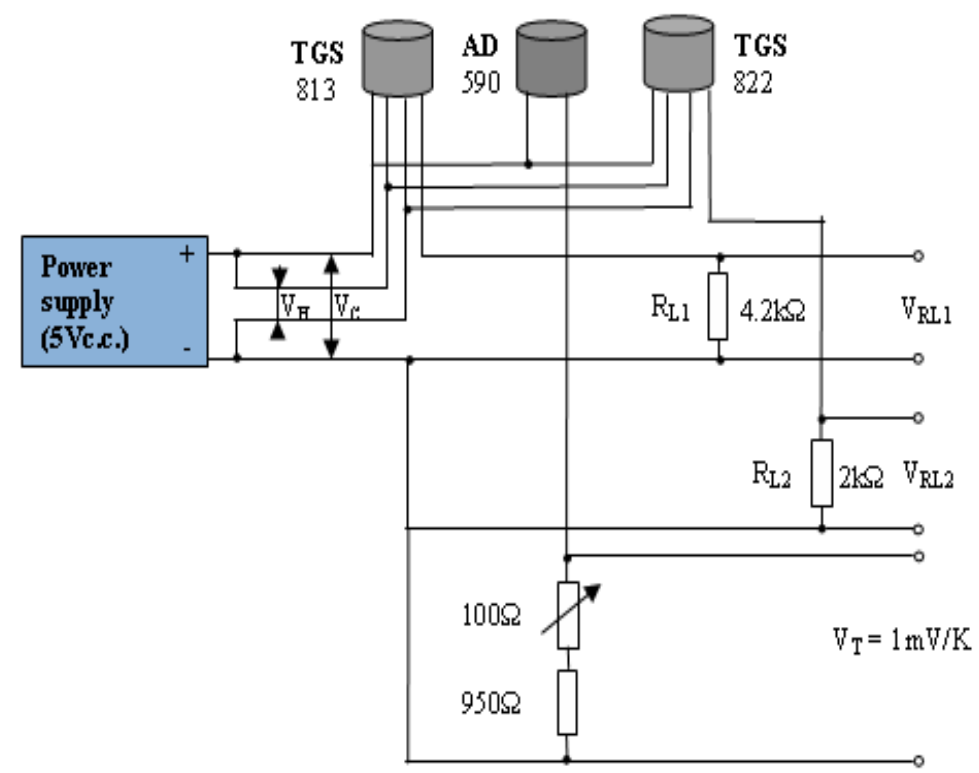

Fig. 5. The signal conditioning circuit.

\subsection{Driver and LabVIEW library}

Using LabVIEW software that has the capability to communicate with the serial port by Inport-Output functions, a driver for this data acquisition board was made it. We created two basic functions Write.vi (Scrie.vi) and Read.vi (Citeste.vi) which are the main functions when communicate with DAQB. The Write and Read functions are used for writing and reading into/from DAS registers. 


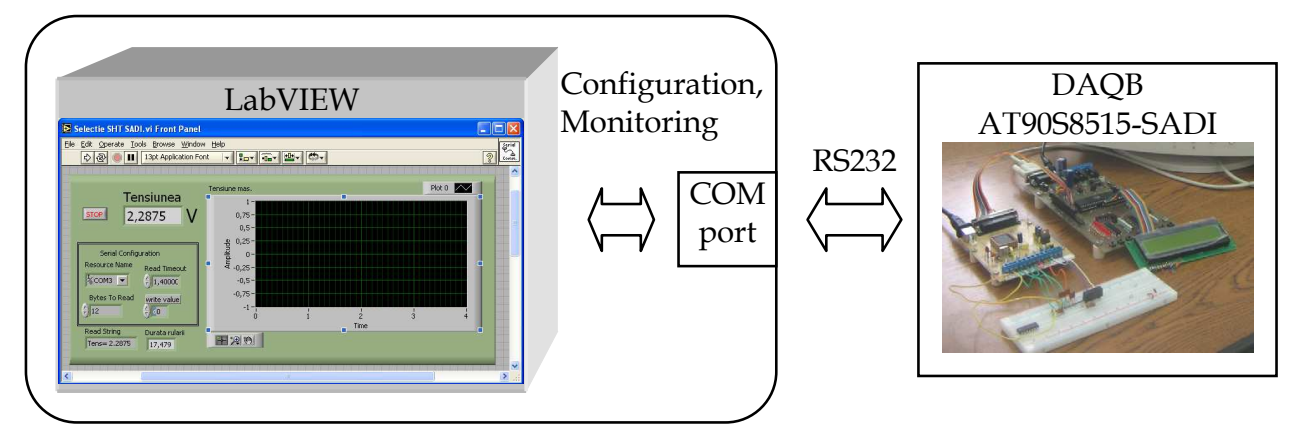

Fig. 6. Configuration and monitoring architecture.

Based on functions Write and Read others complex functions are developed and consists in multiple writing and reading operations into and from the board registers using the basic functions. Each is responsible with specific procedures in the board operation. The functions of the virtual library in LabVIEW environment include:

1. One Push One Channel (acquisition with external start conversion),

2. One Push Multi Channel (acquisition with external start conversion),

3. One Scan One Channel (acquisition without external start conversion),

4. One Scan Multi Channel (acquisition without external start conversion),

5. Waveform multi channel acquisition by interruption,

6.Watchdog/One Push -one channel and acquisition

7.Watchdog/One Push -one channel without acquisition

8.Watchdog/One Push -multi channel and acquisition,

9.Watchdog/One Push -multi channel without acquisition,

10.Watchdog/One Scan -one channel and acquisition,

11.Watchdog/One Scan -one channel without acquisition,

12.Watchdog/One Scan -multi channel and acquisition),

13.Watchdog/One Scan -multi channel without acquisition,

14.Watchdog/Waveform -without acquisition for one channel,

15.Watchdog and alarm without acquisition multi channel.

For LabVIEW, the functions are constituted as sub-VIs that are included into a separate acquisition subpalette, part of the main function palette. The main function palette of the DAQB is LPT-DAS and palette includes other subpalettes:

1.Analog Input,

2.Calibration and Configuration,

3.Timer,

4.Signal Condit.,

5.Wachdog.

In figure 7, subpalettes of Analog Input and Wachdog are presented. 

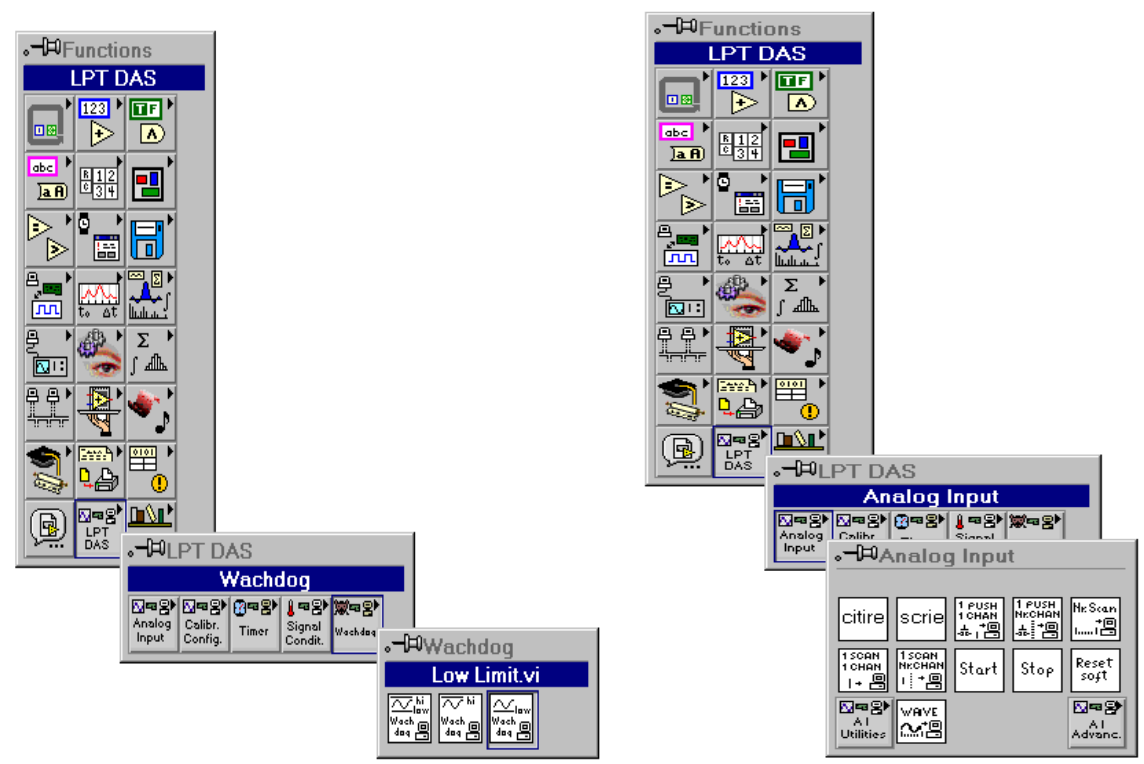

Fig. 7. The functions palette used for communicating with the new DAQB.

The Analog Input subpalette functions contain other tow subpalette functions and simple functions like Write, Read, Start, Stop or Reset (internal sequencer).

Wachdog subpalette contains three functions: Low Limit, High Limit and Low \& High Limit.

No conversion is performed in the watchdog mode, but the DAS samples the selected input(s) and compares it/them with values of the low and high limits stored in the instruction RAM. This comparison is done with a voltage comparator with one comparator input being the selected multiplexer input (pair) and the other input being the appropriate tap on the internal capacitive ladder of the converter. $\mathrm{T}$ his tap is selected by a programmed value in the instruction register. If the input voltage is outside of the user defined and programmed minimum/maximum limits, an interrupt can be generated to indicate a fault condition, and the host processor could then service that interrupt, taking the appropriate action.

The flow diagram of the Watchdog One Channel without Acquisition.vi function will be presented. It consists in multiple writing and one final reading operation into and from the board registers. First, the reset operation has to be performed by selecting RAM section $0(\mathrm{RP}=00)$ and write $0002 \mathrm{H}$ to CONFIGURATION register. Next, is loading instruction to INSTRUCTION RAM (set the utilized channel, the reference to ground or to other channel and the load impedance threshold. Afterwards, select the RAM section $1(\mathrm{RP}=01)$ and write $0100 \mathrm{H}$ to CONFIGURATION register. In this moment it is possible to write the Superior Limit. Afterwards, select the RAM section 2(RP=10, write $0200 \mathrm{H}$ to CONFIGURATION register) and write the Inferior Limit. Start the DAS conversion by setting D0 of CONFIGURATION register high. Read the results of conversion from the Limit Status. 


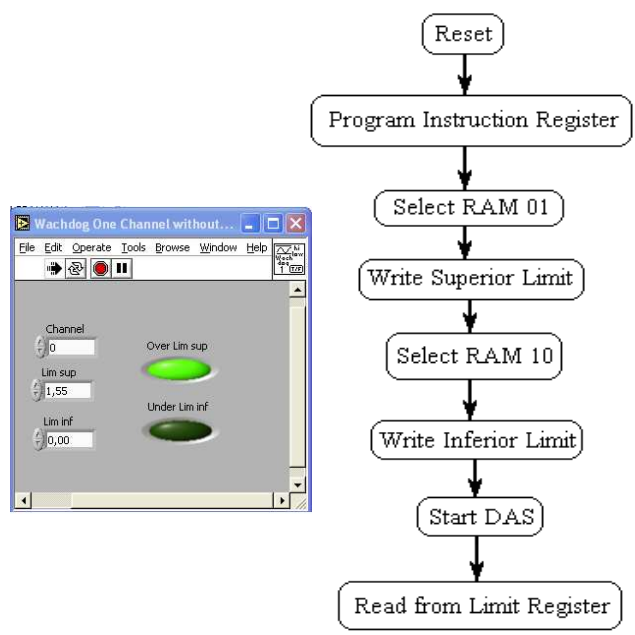

Fig. 8. The flow chart of the Watchdog One Channel without Acquisition.vi.

The Limit Status Register is likewise cleared whenever (Limit Status Register) is read or a device reset is issued.

\section{Virtual instrument}

The virtual instrument is the main part of the monitoring system and, in the same time, the human interface, providing parameters control (Fig.8). The main functions of the VI are:

1. SADI programming and communication control using Nr.Scan function from the specific functions palette.

2. data processing after data reading from SADI analog input channels

3. environmental temperature calculus starting from the analog input voltage $(\mathrm{CH} 2) \mathrm{V}_{\mathrm{T}}$.

$$
\mathrm{T}=\mathrm{V}_{\mathrm{T}} \cdot 1000-273,15\left[{ }^{\circ} \mathrm{C}\right]
$$

4. sensors resistance calculus starting from $\mathrm{CH}_{0}$ and $\mathrm{CH}_{1}$ read voltages ( $\mathrm{V}_{\mathrm{RL} 1}$ and $\mathrm{V}_{\mathrm{RL} 2}$ ):

$$
\mathrm{Rs}=\frac{\mathrm{V}_{\mathrm{C}} \times \mathrm{R}_{\mathrm{L}}}{\mathrm{V}_{\mathrm{RL}}}-\mathrm{R}_{\mathrm{L}}[\Omega]
$$

5. Mean pollutant concentration calculus for a user presetting time interval (ppm/30min, ppm/8h, ppm/24h) for pollution level testing.

6. Pollution agent concentration limits exceeding verify for knowing the immediate effects fort health, lighting and voice user warning

7. Decrease the environmental temperature influence using a compensation subVI

8. Data base saving. 


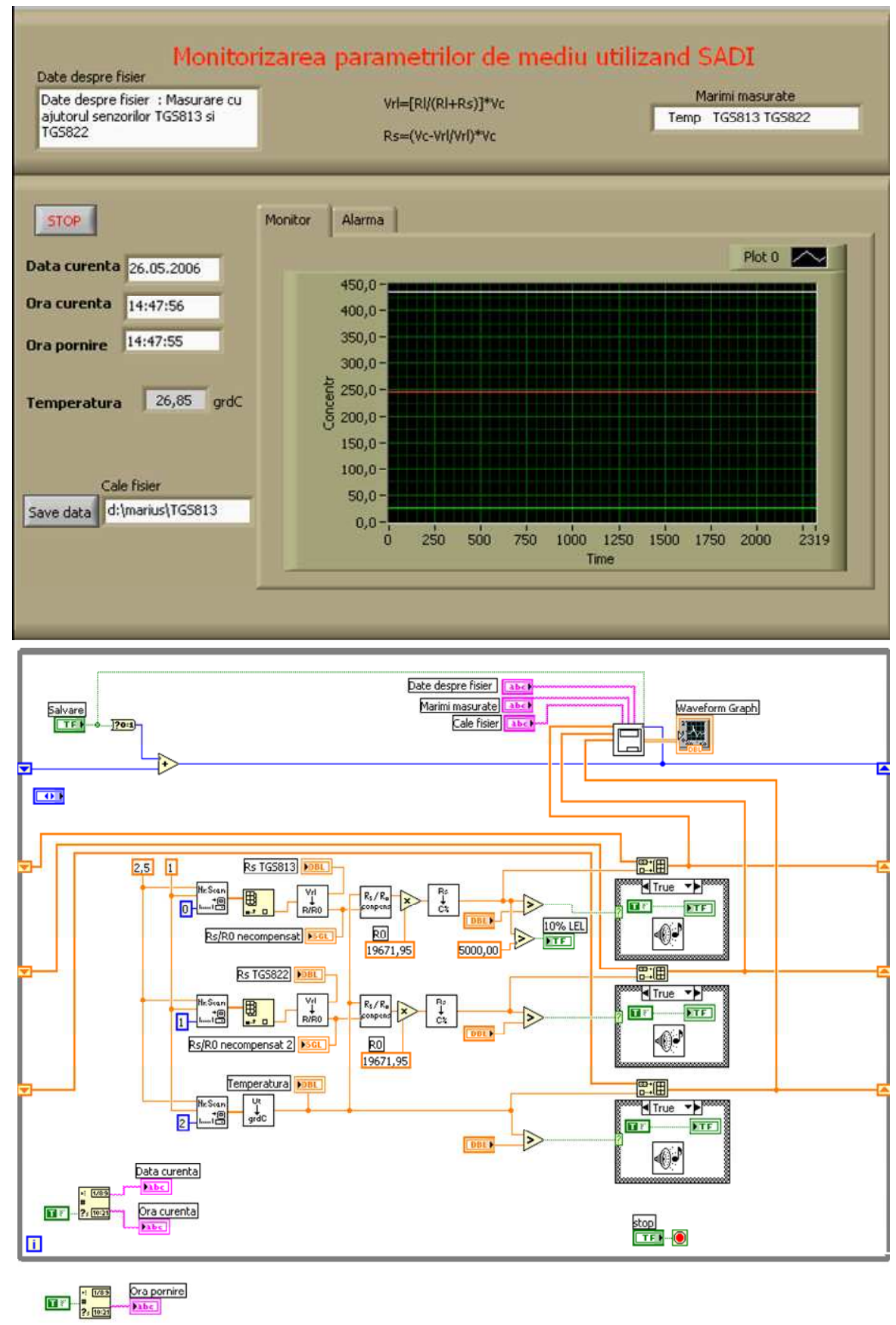

Fig. 8. Front panel and diagram of VI environmental monitoring system. 
Admitting that the temperature and humidity have a great influence to Taguchi sensor resistance we have to make a compensation of the effect very utile when the system is used for outside. Knowing the $\mathrm{RS} / \mathrm{R} 0=\mathrm{f}(\mathrm{T})$ dependency characteristic of the sensors and the temperature from AD590 temperature sensor the VI realize a temperature compensation by parts.

At $65 \%$ relative humidity, a characteristic linearization is made on the next intervals: $-10^{\circ} \mathrm{C} \div$ $20^{\circ} \mathrm{C}, 20^{\circ} \mathrm{C} \div 30^{\circ} \mathrm{C}, 30^{\circ} \mathrm{C} \div 40^{\circ} \mathrm{C}$. A slope determination for the three straight lines is done and for each temperature values is established the compensation factor. The main sub-VI's are:

1.Nr.Scan do the samples acquisition from an analog input channel.

2. Vrl to RpeR0.vi do the determination of $\mathrm{Rs} / \mathrm{R}_{0}$

3.Compens_term.vi realizes the compensation of temperature influence on sensor resistance (TGS). The VI inputs are: current temperature $\left({ }^{\circ} \mathrm{C}\right)$ and measured value of $R s / R_{0}$. The VI output is $R_{S} / R_{0}$ value after thermo-compensation. The compensation of temperature influence is realized by equation implementation of linear variation $R_{S} / R_{0}=f(T)$ on temperature interval previously mentioned.

4. $R$ to Concentratie.vi determine the methane concentration based on sensor measured resistance using the next equation:

$$
\mathrm{G}_{\mathrm{S}}=\mathrm{S}_{0} \cdot \mathrm{C}^{\mathrm{b}}
$$

where,

$\mathrm{G}_{\mathrm{S}}=1 / \mathrm{R}_{\mathrm{S}}$ is the sensor conductivity at certain methane concentration $C$.

$\mathrm{S}_{0}, \mathrm{~b}$ - constants determinate for two concentration $(\mathrm{C} 1=1000 \mathrm{ppm}, \mathrm{C} 2=3000 \mathrm{ppm})$ when we know the value of sensor resistance. At VI input is applied the sensor resistance $\left(R_{S}\right)$ after the thermal effect compensation obtaining to the output the calculated value of concentration.

5. Tens to grdC.vi give the temperature dependence on input voltage of analogical channel $2(1 \mathrm{~m} / \mathrm{K})$.

However, in some situation is necessary the identification (recognize) of some gases compound with different smells using complex chemical analyzes.

If the imitation of tactile, additive and visual human senses and there implementation in tele-transmitting automat systems is well known in the literature, the smell sense was ignored. They are many applications where so called electronic nose may detect what is difficult or impossible for human or animal nose (for example, toxic waste identification, combustible mixture analyze, industrial emission monitoring, noninvasive medical analyzes, verification of food qualities, drugs detecting, mine and explosive detecting).

Intelligent system achievement which is dedicated for particular application is not easy. It presumes a selection of chemical sensors area which provide a large information quantity and complex algorithms development for signal processing.

\section{Web E-Nose System}

For ages, the human nose has been an important tool in assessing the quality of many products, food products being good examples. While all others parts of production processes, including these of the food industry, were getting more and more automated, 
there was still no "objective" means for using the "subjective" information confined in the smell of products. This changed in 1982, when Persaud and Dodd introduced the concept of an electronic nose. They proposed a system, comprising an array of essentially non-selective sensors and an appropriate pattern recognition system, often called "e-nose".

The task of an electronic nose is to identify an odorant sample and perhaps to estimate its concentration. The E-Nose consists of two main components: an array of gas sensors, and a pattern-recognition algorithm. Electronic odour sensing systems can include a combination of hardware components such as sensors, electronics, pumps, fans, air conditioners and flow controllers, and software for hardware observation and data processing. The gas sensors most commonly used in electronic noses are based on metal oxide semiconductor and conducting polymer techniques. Metal oxide sensors were first produced in Japan in the 1960s for use in gas alarms and depend on an alteration in conductance caused by contact with the odour and the reaction that result.

The proposed Web E-Nose consists of three main components: an array of gas sensors, a pattern-recognition algorithm and an Ethernet module with a static IP.

We developed a simple and original WebE-Nose prototype to test pattern recognition techniques that are necessary for building remote electronic nose systems.

Gas sensors tend to have very broad selectivity, responding to many different substances. This is a disadvantage in most applications, but in the electronic nose, it is an advantage. Although every sensor in an array may respond to a given chemical, these responses will usually be different.

Sensor array "sniffs" the vapors from a sample and provides a set of measurements. The pattern-recognizer compares the pattern of the measurements to stored patterns for known materials (Branzila M 2007).

The implemented Web E-Nose system consists in three main components (Fig. 11):

1. a gas sensors array,

2. the pattern recognition algorithm, and

3. Ethernet with IP static module.

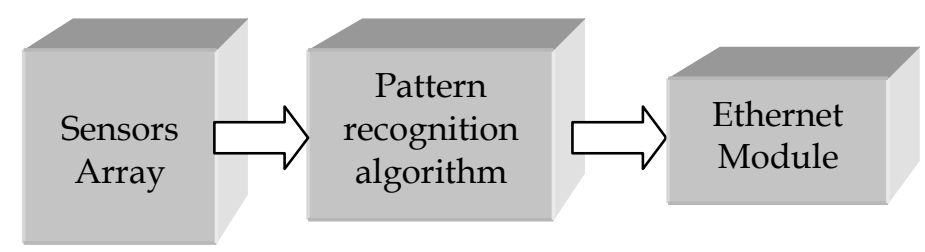

Fig. 9. Main components of the Web E-Nose.

The initial experiment was performed with a number of low selectivity gas sensors calibrated to identify a threshold value of the most important polluting gases occurring in the atmosphere, combined with SHT11 humidity and temperature sensor, allowing immediate temperature and humidity compensation. The sensor array was also trained to recognize, by different sets of measurements, the hazard patterns for different polluting factors acting in the monitored area, as well as identify accidental patterns of polluting factors with external causes. The Ethernet module, having a static IP, give the possibility to share, over the World Wide Web, information's about "remote polluters and potential 
effects, hazard level etc." with a clear identification of the instrument and area. Finally, the result of Web E-Nose expertise may be visualized either as a code image of a given combination of volatile compounds, or may offer a review of the concentrations of individual molecule species detected in a complex environment (Fig. 10).

The response of the sensor array is numerically converted using a prototype data acquisition system SADI (integrated data acquisition system). This response is registered by microcontroller as "case pattern", compared and classified with the ones predefined within the training library. The microcontroller, playing the role of Web E-Nose "brain", communicates with SADI or with IP-Static module server by a serial interface.

Hence, the most important function of the Web E-Nose system consists in detecting and evaluating toxic gases or mixtures at minimum threshold quantities, especially those odourless to human senses. The information, acquired by the gas sensor arrays and rough calibrated by SHT11 temperature and humidity sensor, is subject of further processing for pat-tern recognition and transmission to the decision block by RS232 protocol to the Ethernet server.

The Web E-Nose system has five sequential stages: pre-processing, feature extraction, classification, decision making and decision transmission to the network. The decision making, based on pattern recognition, is assisted by a neural network with both training and extraction functions.

It goes without saying that the Web E-Nose system was not projected to substitute human capability of detecting hazardous situations by "smelling". In addition, the exquisite sensitivity of the dog's nose for sniffing out odours associated to drugs or other hazardous vapours has not yet been matched by currently designed E-nose.

But the system is well suited for repetitive and accurate measurements, and provided not to be affected by saturation, a common disadvantage of natural smelling senses.

Our human nose is elegant, sensitive, and self-repairing, but the Web-E-Nose sensors do not fatigue or get the "flu". Further, the Web-E-Nose can be sent to detect toxic and otherwise hazardous situations that humans may wish to avoid. Sensors can detect toxic CO, which is odorless to humans. And humans are not well suited for repetitive or boring tasks that are better left to machines. No wonder the E-Nose is sometimes referred to as a "sniffer".

However, the human nose is still preferred for many situations like the selection of a fine wine or to determine the off-odor of recycled plastics. In addition, the exquisite sensitivity of the dog's nose for sniffing out drugs or contraband at an airport is legendary already. These skills have not yet been matched by any currently designed E-Nose. 


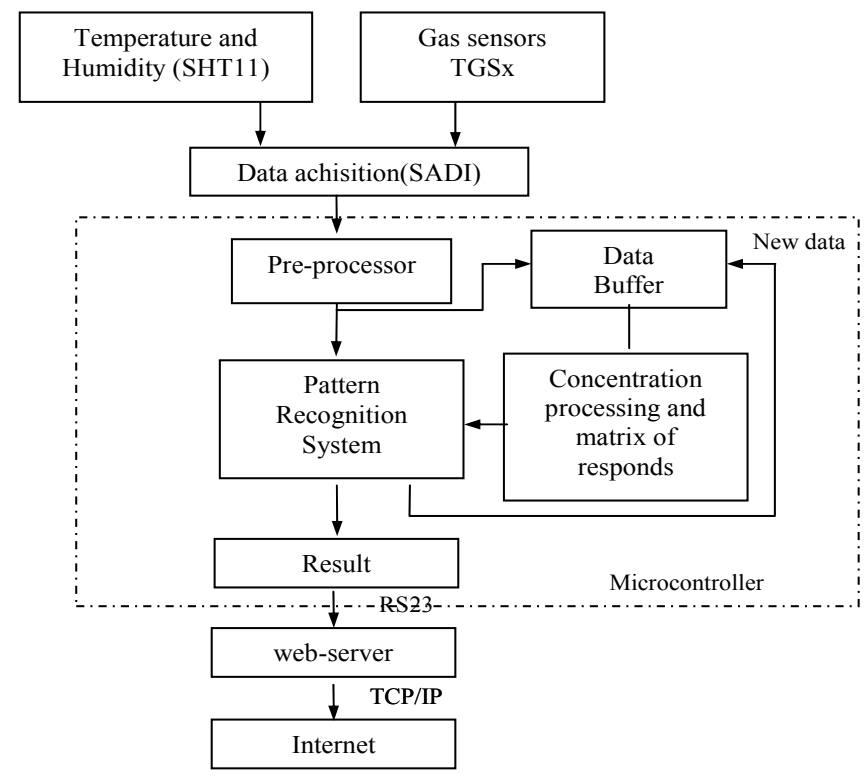

Fig. 10. Web E-Nose communication architecture.

\section{Instrumentation and virtual laboratory}

The Web concept itself is changing the way the measurements are made available and the results are distributed/communicated. Many different options are occurring as regards reports publishing, data sharing, and remotely controlling the applications.

The low-cost availability of new communication tools based on Internet is opening more and more horizons to remote teaching. Interactive on-line tutorials based on World Wide Web (WWW) sites now can be followed directly on the web site. The hardware of monitoring systems (sensors, conditioning circuits, acquisition and communication) must usually be complemented with processing blocks to perform different tasks associated to one-dimensional or multi-dimensional data that flow on the system measurement channels.

The recent wide diffusion of (i) easy-to-use software tools for the implementation of Graphical User Interfaces (GUIs); and (ii) communication-oriented instrumentation, often provided with Ethernet interface, in addition to the more traditional GPIB and RS-232 ones, can be particularly exploited in the field of measurement teaching. It is well known, in fact, that for a better understanding of the teaching issues in such a field, the students have to practice with real instrumentation. The computer-based simulations are often inadequate to assure a good experience in that direction. The tools mentioned above give the possibility of accessing real measurement instrumentation from a remote location, such as the students' homes (Arpaia P\& Daponte P 1996, 1997, 2000). Moreover, it could be possible to repeat the same experience many times in order to make all students able to operate the measuring instrumentation without devoting expert technicians to such activity for many days [11-15]. In measurement teaching, the great increase of students on the one hand, and the reduced number of technicians on the other, greatly requires the possibility of accessing real 
measurement instrumentation for remote experiments (Donciu C, 2001), (Donciu C \& Rapuano C, 2002).

In electrical and electronic measurement courses, particularly, these problems become more severe as consequences of the more sophisticated and expensive apparatus now avail-able which makes it difficult to keep the technical staff up-to-date, and the necessity for repeating the same experience many times in order to make all students able to operate the measuring instrumentation.

There are two basic options when it comes to atmospheric monitoring: use of portable gas detectors or use of fixed detection systems. Portable monitors are battery-operated, transportable devices worn by the person using it and generally can detect only few gases at a time. There are places where many potentially hazardous gases can be permanently present: refineries, chemical plants, gas production plants, laboratories, mines, a.s.o. In these cases, a fixed system placed in the area where leaks of potentially dangerous gases likely to occur may provide general continuous monitoring.

The objective of our research is the development of compact fixed systems for real-time monitoring of the air contaminants, suited for gas leak detection, environmental control, worker protection or other industrial applications. In the first stage, we have designed a system capable to detect only several combustible gases, using a Web E-Nose. The monitoring of more air pollutants increases the system complexity.

Our system performs the following main functions: detection of combustible gases (methane, ethanol, isobutane, hydrogen) and concentration measurement of toxic gases (carbon monoxide, hydrogen sulfide, ammonia). The system provides an alarm when the concentration of detected gases in the air reaches a dangerous level: \% LEL (Lower Explosive Limit) - for combustible gases, TLV/TWA (Threshold Limit Value/Time Weighted Average), IDHL (Immediately Dangerous to Life or Health) - for toxic gases.

It can be very useful in the new society information to create a Virtual Laboratory for a remote teaching [3-4].

An adaptive architecture based on web server application is proposed, in order to increase the performance of the server that hosts a dedicated Web site, and customize the Web site in a manner that emphasizes the interests of the clients. The most virtual laboratories normally provide access either to one remote application, or accept only one user at a time. The system presented below provide a multitask connection, with possible variants for remote education. In this way, two parts compose the architecture of the system:

- client user that uses a client computer and

- measurement provider who disposes the server with the web site of the virtual laboratory.

The users will be able to perform the lab work, controlling the applications and accessing the virtual library. Number of users connected in the same time is unlimited.

The LabVIEW environment was incorporated in centre concept towards creating a unique and powerful distributed application, combining together different measurement nodes and multiple users into a unique measurement controlling system, in order to integrate and revolutionize the fundamental architecture of actual PC-based measurement solutions. All communication software is designed under LabVIEW graphical programming language. In the figure 11 is presented the main web page of application 


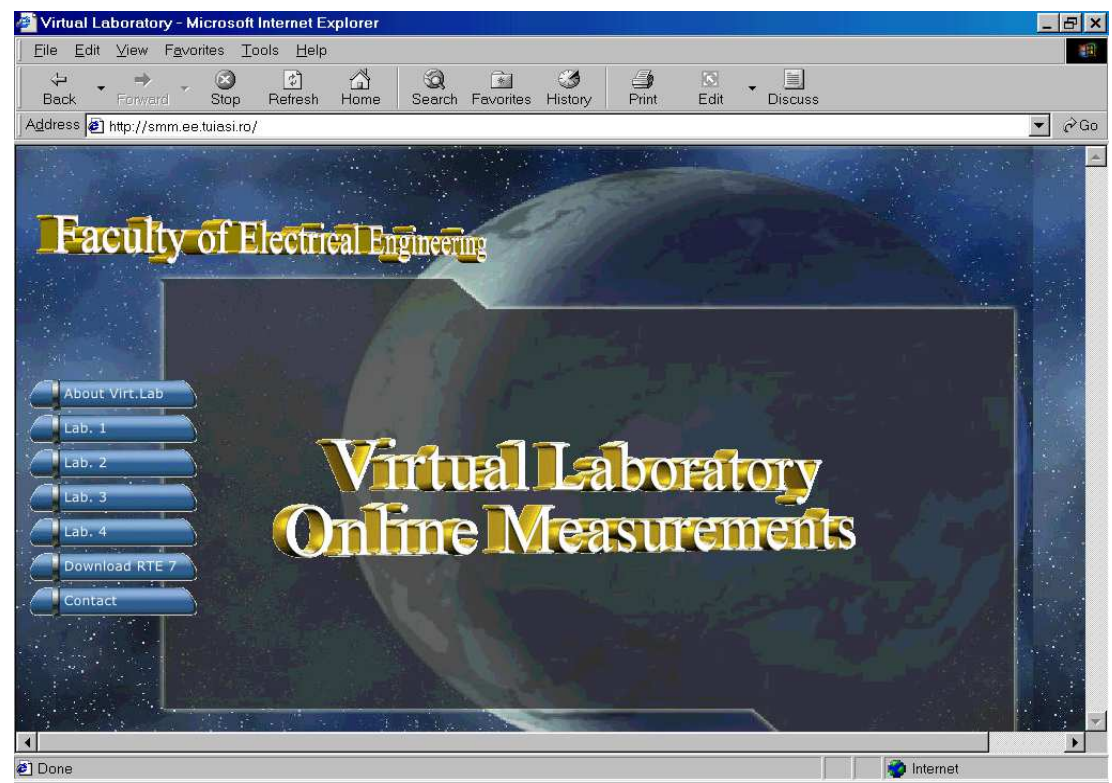

Fig. 11. The main web page of Virtual Laboratory.

\section{Instrumentation and next generation Grid}

The Grid technologies are introduced to build e-Learning environments for engineering education. Service-oriented Grids open new fields of applications, the Learning Grids. The learning services concept based on a learning model and their deployment through Grid technologies are excellent means to integrate virtual laboratories into e-Learning environments for engineering education. Examples from a virtual laboratory demonstrate the advantages of a Grid.

Remote or virtual laboratories with real or simulated experiments are becoming accepted in the engineering community for providing distance education and for augmenting traditional laboratories. Students have to modify instruments for a better understanding of the principle on which the plant operates. They even have to set their own conditions. From a pedagogical point of view, in this kind of environments the student has an active and central role in the learning process. Learning activities are inherently aimed at aiding the construction of knowledge and skills in the student, rather than the memorization of information. In keeping the student at the centre of the learning process, personalization and individualization become relevant aspects to be supported by technologies through the creation of the right context. The students can learn through direct experiences. So, the question remains - how do we provide better means for e-Learning environments combined with virtual laboratories while maintaining or improving the quality of learning by new information and communication technologies. A Learning Grid can contribute to the achievement of these objectives through the definition of the learning services concept and their deployment through Grid technologies. 
Grids yield significant benefits to applications. A Grid is considered as a collection of clustered computational machines, the nodes. In order to have a powerful supercomputer by a Grid the computational problem has to be split into slices and assigned to these nodes. Each node processes its slice individually and after the completion of its slice the results are put back together. Grid nodes do not need to be placed in one geographic location; moreover, machines collaborating in the Grid may have different architectures and operating systems. It is obvious that these nodes need to communicate with each other based on some standards. Therefore a vital topic of security is involved for the interchange of data between nodes. Depending on the application the data should be kept confidential and protected from undesired external changes. Also other issues must be addressed, e.g. redundancy of nodes, quality of service and scalability.

The Grid is applicable only for tasks that can be easily split into smaller slices and that do not require the characteristics of a real-time challenge. In order to reduce the complexity of a Grid, a special layer is introduced that is for gluing the nodes on a logical level. This layer of software sandwiched between the operating system and the applications is commonly called middleware. During recent years a new approach for building Grids has emerged. Instead of perceiving the Grid nodes only as computational elements of an infrastructure they became providers of services. This shift, from strict computational capabilities to service suppliers, opens new fields of applications for Grids. The nodes, instead of only delivering their computational and storage capacity, are now regarded as providers of particular services. They may be parts of some code existing in multiple instances allowing the parallelization of the execution of an application. This new Grid philosophy allows perceiving it in analogy to the commonly known concept of power grids, where the consumer is not aware where and how the power is exactly produced. The consumer only receives the final product with a defined quality.

Figure 12 presents basic interactions between elements of a service-oriented Grid. Services published into a Grid Registry are queried and when discovered then instantiated depending on the user request. Mainly for sake of efficiency the client's communication with the service is direct but may also be virtualized.

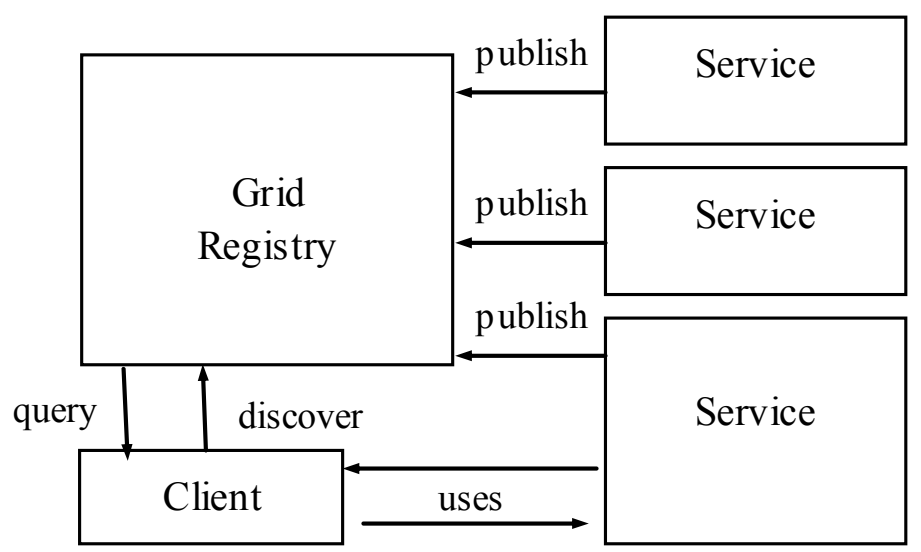

Fig. 12. Structure of a service-oriented Grid environment. 
The main functionalities delivered by the middleware of a service-oriented Grid are:

1. Location - allows the determination, whether the required service exists and at which locations it is accessible

2. Instantiation - allows the instantiation of the service on that host, which matches the capabilities required for the service running with a given quality of service.

3. Orchestration - allows the dynamical composition of more complex services.

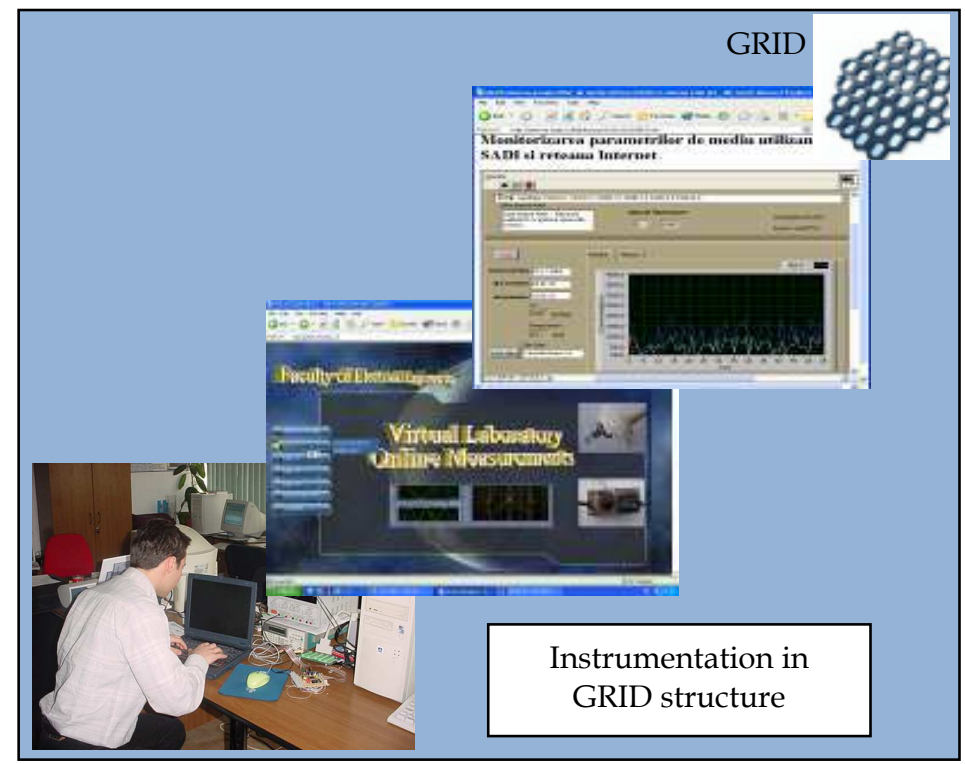

Fig. 13. From real world instruments to Grid structure, through Virtual Laboratory.

Learning Grids contribute to the achievement of the objectives given in the introductory chapter to this article through the definition of the learning services concept and their deployment through Grid technologies. Learning services will be consumed in dynamic virtual communities based on communications and collaborations where learners, through direct experiences, create and share their knowledge in a contextualized and personalized way.

This way of learning using grid resources can become now more open to learners in the engineering domain. The application of Grid technologies in education is of course a much wider topic than presented in this article and by the practical example of a virtual control laboratory. Nonetheless the most important aspects of utilizing service-oriented Grids in distance learning for control education are presented.

\section{Conclusion}

The presented system constitutes a versatile, flexible, cheap, high-speed digital data acquisition system that combined with LabView software give the possibility to easily monitoring the environmental parameters. They are many applications where the system can be used like: toxic waste identification, combustible mixture analyze, industrial emission 
monitoring, non-invasive medical analyzes, verification of food qualities, drugs detecting, mine and explosive detecting.

This system can be adapted for an intelligent electronic nose with data transfer directly through the internet. I named Web E-Nose.

The Internet continues to become more integrated into our daily lives. This is particularly true for scientists and engineers, because designers of development systems view the Internet as a cost-effective worldwide standard for distributing data.

The paper presents the architecture of a versatile, flexible, cost efficient, high-speed measurement centre, based on remote instrumentation, and having as final purposes the monitoring of the air quality and the advertising of the air pollution. On the other hand the E-Medicine becomes a very interesting domain for physicians and bioengineers. That for the purposed system can be very useful tool for them.

In many locations a basic infrastructure to evaluate the E-Medicine already exists, but a unitary concept of an E-Medicine centre can be used to deliver services of comparable or higher quality, at a clear lower cost and a higher speed and reliability.

The Web-E-Nose system was tested, and provided to be well suited for repetitive and accurate measurements, without being affected by saturation. But the successful implementation of such Web E-Nose concepts for air pollution evaluation at larger scales will require a careful examination of all costs, either direct or indirect, and should demonstrate its societal benefit over time.

The remote and distributed measurement system developed as environmental centre may be also particularized as virtual laboratory for on-line environmental monitoring, helping the formation of well trained specialists in the domain.

The Web E-Nose is a tool that may be used for safety, quality, or process monitoring, accomplishing in a few minutes procedures that may presently require days to complete.

The system performs good and fast measurement, processing and transmission of the odors. It is very useful in the new society information to create a Virtual Laboratory for a remote teaching or to get information about gas mixtures or odours from a remote site.

The application of Grid technologies in education is of course a much wider topic than presented in this article and by the practical example of a virtual control laboratory. Nonetheless the most important aspects of utilizing service-oriented Grids in distance learning for control education are presented.

\section{References}

Arpaia P., Daponte P. (2000), A measurement laboratory on geographic network for remote test experiments, IEEE Trans. on Instrumentation and Measurement, vol. 49, No. 5, Oct. 2000, pp. 992-997.

Arpaia P., Daponte P. (1997) Ethernet application perspectives for distributed measurement systems, Proc. of XIV IMEKO World Congress, June 1997, Tampere, Finland, vol. IVA, pp. 13-18.

Arpaia P., Daponte P. (1996) A distributed laboratory based on object-oriented systems, Measurement, vol. 19, No. 3/4, Nov.-Dec. 1996, pp. 207-215. 
Bertocco M., Cappellazzo S., A. Carullo, M. Parvis, A. Vallan, “Virtual environment for fast development of distributed measurement applications", Proc. of IEEE International Workshop on Virtual and Intelligent Measurement Systems, VIMS 2001, Budapest, Hungary, May 2001, pp. 57-60.

Branzila M., and Co., A complex system for environmental monitoring with a prototype data acquisition board, IMEKO 2004 - 13th International Symposium on Measurements for Research and Industry Applications - 9th Workshop on ADC Modelling and Testing files, Athens - Greece, ISBN 960-254-645-X, pp.428-430

Branzila M.C, and Co., Virtual Library Included in LabVIEW Environment for a New DAS with Data Transfer by LPT, IMEKO 2005 - 14th International Symposium on New Technologies in Measurement and Instrumentation and 10th Workshop on ADC Modelling and Testing, 12-15 September 2005, Gdynia/Jurata Poland, ISBN 8389786-37-0, pp.535-540

Branzila M., Alexandru C.I., Donciu C., Cretu M., Design and Analysis of a proposed Web Electronic Nose (WebE-Nose), EPE 2007 12th-14 th Oct, IAŞI - ROMÂNIA Buletinul IPI, Tomul LII(LIV), Fasc. 5

Branzila, M., Alexandru, C., Donciu, C., Virtual environmental measurement center based on remote instrumentation, Environmental Engineering And Management Journal, Vol. 6, pp. 517-520, nov-dec 2007

Branzila M. (2008) Intelligent system for monitoring of exhaust gas from hybrid vehicle, Intelligent Systems, 2008. IS '08, 4th International IEEE Conference, Volume 1, 6-8 Sept. 2008, Varna, Bulgaria, Page(s):5-2 - 5-5, ISBN: 978-1-4244-1739-1

Branzila M. (2008) New DAQB and associated virtual library included in LabVIEW for environmental parameters monitoring, VECIMS 2008 IEEE Conference, 14-16 July 2008, Istanbul, page(s): 121-124, ISBN: 978-1-4244-1927-2, INSPEC Accession Number: 10156672

Branzila M. (2007), Virtual environmental measurement center based on remote instrumentation, ENVIRONMENTAL ENGINEERING AND MANAGEMENT JOURNAL, Volume: 6, Issue: 6, pp. 517-520

Branzila M. (2007) Virtual meteorological center, International Journal of Online Engineering, Vol. 3, No. 4 , 2007, pp. 45-480

Branzila M. (2006) Design and Analysis of a proposed Web Electronic Nose (WebE-Nose), IAŞI - ROMÂNIA Buletinul Institutului Politehnic din Iasi, Tomul LII(LIV), Fasc. 5, 2006, ISSN 1223-8139, pp.971-976

Carlosena A., Cabeza R. (1977), A course on instrumentation: the signal processing approach, Proc. of IEEE IMTC-97, Ottawa, Canada, May 1997, pp. 1326-1331.

Donciu C., Petrescu M., Branzila M.C., Cantemir L., Cretu M., Prototype For A Distributed Measurement System, 4th International Conference On Electromechanical And Power Systems, September 26-27, Chisinau, Moldova, pp187-188, 2003

Donciu, C., Temneanu, M., Branzila, M., Sustainable irrigation based on intelligent optimization of nutrients applications, Environmental Engineering And Management Journal, Vol. 6, pp. 537-540, nov-dec 2007

Donciu, C., Temneanu, M., Branzila, M., Urban traffic pollution reduction using an intelligent video semaphoring system, Environmental Engineering And Management Journal, Vol. 6, pp. 563-566, nov-dec 2007 
Donciu C, Cretu M. (2001) Communication in Virtual Instrumentation", Management of technological changes, Iasi, Romania, pp 69-74

Donciu C, Rapuano S. (2002) A Remote Inter-University System for Measurement Teaching 12th IMEKO TC4 International Symposium, Zagreb, Croatia, pp 420-424

Dyer S.A., Dyer R.A. (1977)Emphasizing the interdependence of topics in required undergraduate electrical engineering courses: a case study, Proc. of IEEE IMTC-97, Ottawa, Canada, May 1997, pp. 1320-1325.

Hancock N.H. (1977), I\&M in the 21st century engineering curriculum-a direction for change, Proc. of IEEE IMTC-97, Ottawa, Canada, May 1997, pp. 1326-1331.

Keller P.E., Kouzes R.T., and Kangas L.J., “Three Neural Network Based Sensor Systems for Environmental Monitoring," IEEE Electro 94 Conference Proceedings, pp. 377-382, IEEE Press, Piscataway, NJ, USA, 1994

Keller P.E. (1996), Electronic Noses and Their Applications, Proceedings of the World Congress on Neural Networks'96, pp. 928-931, Lawrence Erlbaum Associates Inc., Mahwah, NJ, USA, 1996.

Schreiner C., Branzila M. (2006), Air quality and pollution mapping system, using remote measurements and GPS technology, Global NEST Journal, Vol 8, No 3, ISSN 17907632, pp 315-323, 2006 


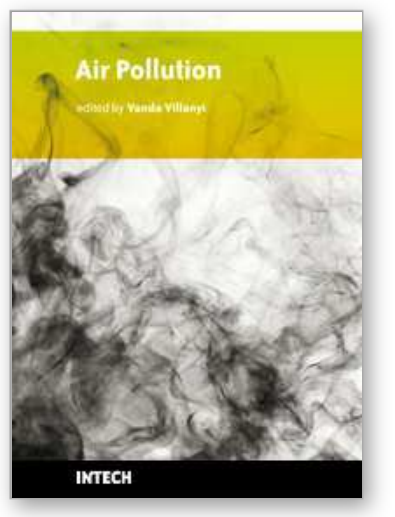

\author{
Air Pollution \\ Edited by Vanda Villanyi
}

ISBN 978-953-307-143-5

Hard cover, 370 pages

Publisher Sciyo

Published online 17, August, 2010

Published in print edition August, 2010

Although the climate of the Earth is continually changing from the very beginning, anthropogenic effects, the pollution of the air by combustion and industrial activities make it change so quickly that the adaptation is very difficult for all living organisms. Researcher's role is to make this adaptation easier, to prepare humankind to the new circumstances and challenges, to trace and predict the effects and, if possible, even decrease the harmfulness of these changes. In this book we provide an interdisciplinary collection of new studies and findings on the score of air pollution.

\title{
How to reference
}

In order to correctly reference this scholarly work, feel free to copy and paste the following:

Marius Branzila (2010). Instrumentation and Virtual Library for Air Pollution Monitoring, Air Pollution, Vanda Villanyi (Ed.), ISBN: 978-953-307-143-5, InTech, Available from: http://www.intechopen.com/books/airpollution/instrumentation-and-virtual-library-for-air-pollution-monitoring

\section{INTECH}

open science | open minds

\section{InTech Europe}

University Campus STeP Ri

Slavka Krautzeka 83/A

51000 Rijeka, Croatia

Phone: +385 (51) 770447

Fax: +385 (51) 686166

www.intechopen.com

\section{InTech China}

Unit 405, Office Block, Hotel Equatorial Shanghai

No.65, Yan An Road (West), Shanghai, 200040, China 中国上海市延安西路65号上海国际贵都大饭店办公楼405单元

Phone: +86-21-62489820

Fax: $+86-21-62489821$ 
(C) 2010 The Author(s). Licensee IntechOpen. This chapter is distributed under the terms of the Creative Commons Attribution-NonCommercialShareAlike-3.0 License, which permits use, distribution and reproduction for non-commercial purposes, provided the original is properly cited and derivative works building on this content are distributed under the same license. 